\title{
An Overview on Dry Eye Treatment: Approaches for Cyclosporin A Delivery
}

\author{
Burçin Yavuz, Sibel Bozdağ Pehlivan, and Nurşen Ünlü \\ Department of Pharmaceutical Technology, Faculty of Pharmacy, Hacettepe University, \\ 06100 Ankara, Turkey
}

Correspondence should be addressed to Nurşen Ünlü, nunlu@hacettepe.edu.tr

Received 31 October 2011; Accepted 21 December 2011

Academic Editors: Z. Bashshur and L. Pablo

Copyright (C) 2012 Burçin Yavuz et al. This is an open access article distributed under the Creative Commons Attribution License, which permits unrestricted use, distribution, and reproduction in any medium, provided the original work is properly cited.

\begin{abstract}
Dry eye syndrome (DES, Keratoconjunctivitis sicca) is a common disorder of the tear film caused by decreased tear production or increased evaporation. Changes in tear composition also promote inflammation on the ocular surface by various mechanisms. Artificial tear drops, tear retention treatment, stimulation of tear secretion, or anti-inflammatory drugs may be used for dry eye treatment according to the severity of the disease. For untreated patients, the risk of ocular infection increases at considerable level and clinical course of the disease may proceed up to infection, corneal ulcer, and blindness. Artificial tears and/or punctual occlusions are used for tear replacement or preservation. New treatment approaches are designed to modify the underlying disease process. For the treatment of severe dry eye disease, cyclosporin A (CsA), the first one of the new generation immunomodulatory drugs, which has an anti-inflammatory effect, is frequently used. CsA has immunosuppressive effects following systemic application. Following local administration of CsA, it is expected to obtain effective drug concentration at the target area and to avoid the various side effects associated with systemic delivery. Microspheres, implants, and liposomes have been developed for administration of CsA subconjunctivally in order to enhance its efficiency.
\end{abstract}

\section{Introduction}

According to the the Dry Eye Workshop (DEWS, 2007) report, prevalence of dry eye ranges from $5-30 \%$ in people aged 50 years and older. Prevalence of DES is estimated that about 3.2 million women and 1.7 million men, for a total of 4.9 million patients 50 years and older, have dry eye. Tens of millions more have mild dry eyes that may be notable only when some adverse contributing factor is present, such as low humidity or contact lens wear $[1,2]$. There is an increase of DES prevalance in recent years due to the general aging of the population as well as the increased use of some certain drugs $[3,4]$. DES is characterized by chronic dryness of the cornea and conjunctiva which is caused by unstable tear film associated with abnormality of the lipid, protein, and mucin profiles [5]. Changes in tear composition resulting from lacrimal dysfunction, increased evaporation, and/or poor clearance have proinflammatory effects on the ocular surface [6].
Typical symptoms of DES include burning, stinging, and photophobia. In addition, patients with chronic, uncontrolled disease may complain about blurred vision, decreased ability to produce tear, and intolerance to contact lenses. Ocular surface abnormalities may develop, including superficial punctate erosions, epithelial defects, corneal filaments and in severe cases, corneal ulcers $[11,12]$. As a result of these symptoms, DES can have a considerable impact on visual function, daily activities, social and physical functioning, workplace productivity, and quality of life [13].

Although DES can arise from various types of diseases, common to all is the involvement of immune-mediated or inflammatory-mediated pathways. One of the major causes of the DES is Sjörgen's Syndorme which is an autoimmune disease usually effecting middle-aged women. It is believed that progressive lymphocytic infiltration is responsible for the destruction of normal secretory function [1417]. Dysfunction of the lacrimal functional unit alters the balance of tear film components, which support and protect 

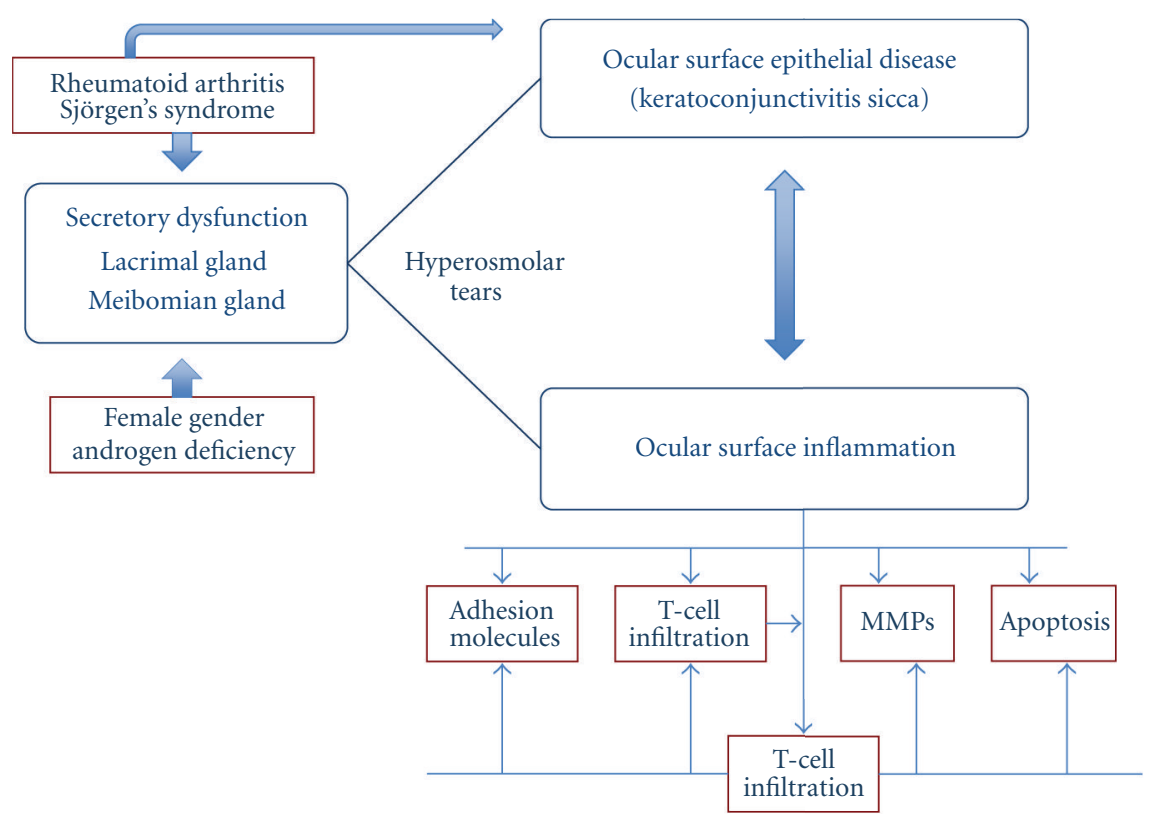

FIGURE 1: Inflammatory mediators in DES. (MMPs: matrix metalloproteinases) [5].

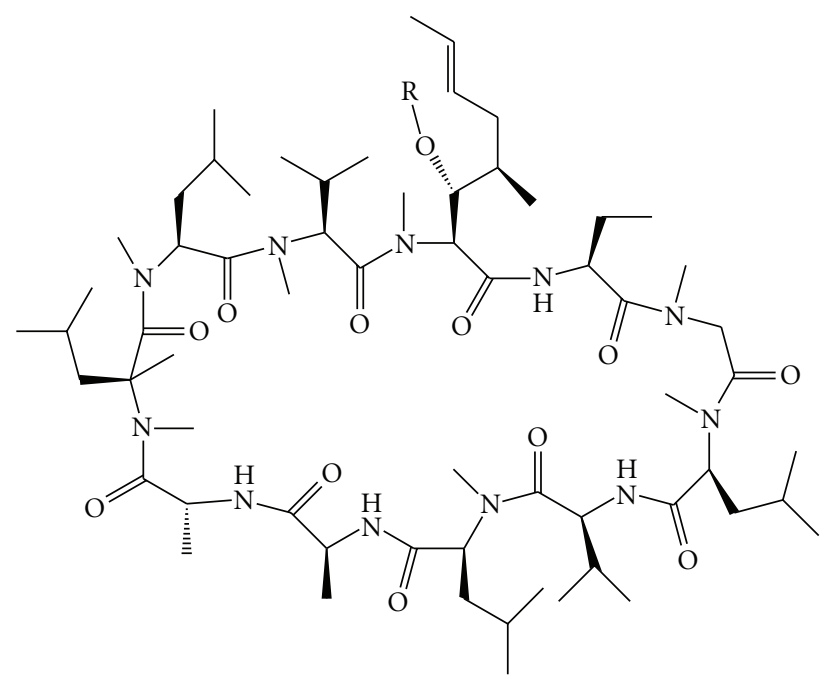

FIgURE 2: The structure of CsA [7].

the ocular surface by stabilizing the tear film. These changes in tear composition also induce inflammation on the ocular surface by several mechanisms (Figure 1). Current lack of understanding makes the diagnosis of DES difficult. Progress in this area should make it possible to characterize, diagnose, and treat DES more effectively [18].

Cyclosporine A (CsA) is a neutral, hydrophobic, cyclic peptide of amino acids which can be isolated from several species of fungi [19]. Its molecular formula is $\mathrm{C}_{12} \mathrm{H}_{111} \mathrm{~N}_{11} \mathrm{O}_{12}$ and its molecular weight is $1202.64 \mathrm{Da}$. CsA molecule contains four intramolecular hydrogen bonds that impart high rigidity to its cyclic structure (Figure 2) [20]. This unusual structure of CsA confers a very low aqueous solubility, causing highly variable and incomplete absorption from its conventional oral or topical formulations. As a result, an uncertain relation between the drug dosage and in vivo exposure observed [7].

Numerous reports support that the local immunosuppression caused by CsA is effective for the management of corneal graft rejection, autoimmune uveitis and dry eye syndrome [21]. It acts as a selective inhibitor of interleukin2 (IL-2) release during the activation of T-cells and causes cell-mediated immune response suppression [22, 23]. CsA's mechanism of action is based on its effects on subconjunctival and lacrimal gland inflammation, resulting in an increase in tear production and conjunctival goblet cell density in a significant number of moderate-to-severe DES patients who received treatment $[24,25]$. Topical CsA (Restasis) is currently the only pharmacologic treatment approved by the US Food and Drug Administration (FDA) specifically for DES. 
Topical rather than systemic CsA application has been suggested that could also be therapeutic, without causing systemic side effects, in the treatment of ocular diseases. This may be possible because much less of CsA can penetrate into the bloodstream after its topical application. It is expected that penetration from an aqueous medium will be even less than in oil due to its low solubility in water. An ideal topical formulation to the eye must fulfill several requirements as follows: the formulation must be well tolerated and easy to administer, increase CsA retention time in the eye, and avoid systemic absorption. Various ophthalmic formulations have been developed to improve ocular penetration, reduce toxicity, and improve tolerability of CsA [26, 27].

\section{Treatment of Dry Eye Syndrome (DES)}

Commonly used etiologic classifications (e.g., aqueous-deficient versus evaporative, Sjögren versus non-Sjögren) often are not helpful in establishing a treatment plan for DES. International Task Force (ITF) guidelines proposing a classification of DES severity based on clinical signs and symptoms were published in 2006. The ITF also developed the treatment algorithms according to classification and the presence of lid margin disease. The ITF treatment recommendations were based on the severity grading of DES symptoms such as discomfort, visual symptoms, corneal and conjunctival staining, lid gland dysfunction, tear break up time, and Schirmer score [28].

2.1. Tear Substitutes. A wide variety of tear substitutions is available as over-the-counter (OTC) products. These products differ from the electrolyte composition, osmolarity, viscosity, the presence of preservatives, and compatible solutes [29].

Preservative-free tear substitutes are the first step in medical management of DES [30]. The goal of using tear substitutes is to increase humidity at the ocular surface and to improve lubrication [31]. Mild cases of DES, in which there are no signs of damage to the conjunctiva or cornea, may be successfully managed with artificial tears applied up to four times per day. In moderate cases of DES, examination will reveal mild damage to the cornea, more frequent treatment will be required [32].

Short-acting preparations are based on carboxy-methylcellulose (CMC) or polyvinyl alcohol (PVA), whereas longer acting artificial tear products contain aqueous carbomer gels or paraffin. A preservative-free $0.5 \%$ hydroxypropyl methylcellulose (HPMC) formula was found to be effective in improving DES symptoms in both Sjögren's Syndrome (SS) and non-Sjögren's Syndrome (non-SS) DES patients, with a significant improvement in conjunctival and corneal staining scores and breakup times [33].

However, the use of artificial tears has some limitations. Natural tears have a complex composition of water, salts, hydrocarbons, proteins, and lipids that artificial tears cannot exactly substitute. Formulations containing additional ingredients have been prepared to increase their contact time with the ocular surface to overcome this problem. These ingredients are designed to have mucoadhesive properties, as they adhere to and simulate the mucous layer of the tear film $[34,35]$. Ludwig et al. used Slit-lamp fluorophotometry to evaluate precorneal kinetics of viscous eye drops containing Carbopol 940, disodium EDTA, and a fluorescent tracer in humans. The results showed that the ocular retention of the tracer depends on the concentration of the polymer instilled and disodium EDTA addition does not improve the precorneal kinetics significantly [36]. Carbopol 940 ophthalmic vehicles were prepared by the same group in order to investigate the interaction between the simulated lacrimal fluid and the polymer. The influence of sodium fluorescein on the physicochemical properties of the polymer vehicles, was also examined. Four kinds of vehicles containing mannitol $(5 \%)$, sodium fluorescein $(0.05 \%)$, and disodium edetate $(0.01 \%)$ were formulated. Regarding the results, three concentrations of Carbopol 940 vehicles $(0.20 \%, 0.15 \%$ and $0.10 \%$ ) were proposed for in vivo evaluation [37]. The rheological behaviours of different types of Carbopol (Carbopol 940, 934, 941, and 910) were also investigated. The aqueous vehicles of Carbopol 940 were found to show excellent appearance and clarity when compared with the other types of polymer [38].

Other common additives used in artificial tear preparations are buffers, which are used to maintain the $\mathrm{pH}$ of human natural tears (7.4) as closely as possible when they are applied to the eye [34]. In addition, hypotonic electrolytebased formulations have been developed based on the recognition of the importance of tear osmolarity [39].

Autologous serum eye drops, which are produced from patient's serum, are also commonly used based on the severity of dryness and presence of associated ocular surface complications. It has similar biochemical and mechanical properties, but not identical, to those of normal aqueous tears [40]. Furthermore, the use of serum eye drops implies the risk of infectious disease transmission from the donor [41].

2.2. Tear Preservation. Occlusion of the lacrimal puncta or canaliculi is a common nonpharmacological therapy for DES. The punctal plugs block the flow of the tears through the canaliculi which connect eyes to the nose. These systems have been claimed to improve the quantity and the quality of the aqueous component of the tear film, relieving the symptoms of DES $[9,42]$.

The decision to block the tear drainage system should be taken with care because of the potential undesired effects of the plugs. Delayed tear clearance can result in increased concentration of proinflammatory cytokines in the tear film, causing desensitization of the corneal surface and promoting inflammation. It is also possible that delayed tear clearance can result in increased toxicity of other ocular medications that the dry eye patient might use $[43,44]$.

2.3. Treating the Causes of DES. Topical steroids target the inflammatory component of DES in a nonspecific manner. This therapy can be considered as a short-term pulse for the inflammation because of the high risk of complications with chronic use [45]. When blepharitis is the underlying cause or a contributory element of dry eye, topical tetracyclines 
have become the treatment of choice $[32,46]$. It was found a positive relationship between hormone levels and tear production in pre- and postmenopausal women and estrogen levels correlated positively with tear function [47]. It has been reported that injection of botulinum toxin in the eyelids produced a decreased lacrimal drainage. The actual clinical efficiency of botulinum toxin injections as a DES treatment has yet to be evaluated [48].

Topical nonsteroidal anti-inflammatory drugs (NSAIDs) have been used off-label in DES treatment. There are two randomized trials with topical diclofenac and topical ketorolac that provide evidence of NSAID efficacy $[49,50]$. Oral pilocarpine has been demonstrated to increase tear production and flow, thus it improves the symptoms of DES in Sjögren's syndrome patients [51].

Vitamin A eye drops are also effective for the treatment of dry eye disorder [52]. An o/w emulsion of $0.01 \%$ all-transretinoic acid (tretinoin, vitamin $\mathrm{A}$ ) was prepared and clinically evaluated in DES patients by Selek et al. It was reported that tear film breakup time was significantly improved by retinoic acid treatment $[53,54]$. In another study, poly (lactic-co-glycolic acid) (PLGA) microspheres containing alltrans retinoic acid were prepared. In vitro release studies showed that retinoic acid release from microspheres lasted for 11 days [55].

CsA has been successfully used as a systemic immunomodulator, motivating extensive research on its mechanisms of action and formulation alternatives. An FDA-approved ophthalmic CsA formulation has been available for only a few years and has been shown to be beneficial in DES. Therefore, the main focus of this review is the delivery systems for CsA, which is one of the recent common treatments in DES.

\subsubsection{CsA Delivery Systems for Dry Eye Syndrome (DES)} Treatment. CsA is one of the greatest discoveries in the history of organ transplantation in the last few decades. In November 1983, the FDA approved CsA for the prevention of transplant rejection and complete chemical synthesis of CsA that was reported by Wenger in $1984[56,57]$.

Topical CsA preparations have been used to treat ocular surface lymphocyte-driven inflammation in animals since 1989 [58]. A commercial product, Optimmune, was approved in 1996 for canine keratoconjunctivitis sicca [83]. Topical $0.05 \%$ CsA has been shown to be an effective therapeutic agent for moderate-to-severe dry eye in phase III clinical trials and in December 2002, FDA approved CsA emulsion (RESTASIS) for treating the inflammatory component of dry eye. This approval represents a major shift in the treatment of dry eye and in our understanding of its pathogenesis $[5,24]$. Pricing models for topical cyclosporine for the treatment of refractory moderate-to-severe dry eye disease are evaluated by Brown et al. [84]. The results indicated that the price of CsA emulsion could be raised $228 \%$ which means that CsA costs much more lower than its worth.

Plenty of studies have been made to overcome the difficulties mentioned above, in introduction part, to increase the therapeutic efficacy of CsA and decrease its side effects by various approaches such as solid formulations, liposomes, emulsions and microemulsions, microspheres, nanoparticles, and physical or chemical enhancers (Table 1). Topical, subconjunctival, and systemic routes have been studied for CsA delivery for the DES treatment. However, intravitreal administration is not a preferred administration route in DES even though it is the usual route for posterior segment disorder therapy.

\section{(1) Topical Administration}

(a) Aqueus Solutions. Various approaches have been studied to solve CsA's aqueous solubility problem. Furrer et al. reported that Cremophor and benzalkonium significantly increased flux rates of CsA across cornea while DMSO has no effect [63]. Benzalkonium is well tolerated at the concentration used in eye drops as preservative $(0.01 \% \mathrm{w} / \mathrm{v})$, but caused ocular irritation at higher concentration $(1 \% \mathrm{w} / \mathrm{v})$ [85]. Cremophor has been associated with changes of corneal surface structure following topical administration [86].

Cyclodextrins (CDs) are cyclic oligosaccharides that are capable of forming inclusion complexes with a variety of guest molecules owing to their special structure, with a hydrophilic external surface and a hydrophobic cavity lined with protons. CDs have the ability to interact with poorly water-soluble drugs and drug candidates resulting in an increase in the drug's apparent water solubility and dissolution rates [87]. It has been reported that solubility of CsA was found approximately 100-fold higher than for CsA alone [88]. Mueller [89] showed that CsA bound to CDs resulted in higher corneal penetration than CsA corn oil solutions. However, this formulation resulted in a very small reservoir effect in the cornea, due to the low intrinsic quantity of drug in the formulation and fast clearance time on the eye surface.

The effect of other penetration enhancers on the transcorneal permeation of CsA has also been investigated. The results have indicated that penetration enhancers have serious limitation of low tolerance of these molecules, due to their modification of corneal properties [64].

It was recently reported that DES can be progressive in patients treated with artificial tears alone, whereas topical anti-inflammatory therapy with CsA $0.05 \%$ may slow or prevent the disease progression in patients with DES. Largescale controlled studies are needed to confirm these findings [90].

(b) Oily Solutions and Ointments. Williams et al. reported that topical CsA in olive oil solution induces a burning sensation and an irritation on the conjunctiva. These side effects have been attributed to the vehicles used [58]. Patients did not complain about these side effects after application of a $2 \% \mathrm{w} / \mathrm{w}$ CsA ointment, and ocular examination supported that there were no significant lesions [91].

A marketed ointment formulation for veterinary use, Optimmune (Schering-Plough, 0.2\% CsA ophthalmic ointment), is approved for the treatment of DES and ocular surface inflammatory diseases in dogs. This formulation is not available for human use because of poor acceptability by patients [92]. 
TABLE 1: Delivery systems developed for CsA delivery to the eye.

\begin{tabular}{|c|c|c|c|c|}
\hline Dosage form/pathway & Delivery system & Advantages & Drawbacks & Reference \\
\hline \multirow{3}{*}{ Topical Solutions } & Oils & $\begin{array}{l}\text { High solubilizing CsA } \\
\text { capacity }\end{array}$ & $\begin{array}{l}\text { Poor tolerance unfavorable } \\
\text { partition }\end{array}$ & {$[58-60]$} \\
\hline & $\alpha$-cyclodextrins $(\alpha$-CD) & $\begin{array}{l}\text { Enhanced corneal } \\
\text { penetration }\end{array}$ & Repeated administrations & {$[61,62]$} \\
\hline & Penetration enhancers & $\begin{array}{l}\text { Enhanced corneal } \\
\text { penetration }\end{array}$ & Poor tolerance & {$[63,64]$} \\
\hline \multirow{9}{*}{ Topical colloidal carriers } & Micelles & $\begin{array}{l}\text { High corneal } \\
\text { concentrations at } 24 \text { hours }\end{array}$ & $\begin{array}{l}\text { Poor tolerance Stability of } \\
\text { micelles }\end{array}$ & {$[65]$} \\
\hline & $\begin{array}{l}\text { Emulsion negatively } \\
\text { charged }\end{array}$ & $\begin{array}{l}\text { Improvement in dry eye } \\
\text { symptoms FDA approved }\end{array}$ & Ocular burning & {$[24]$} \\
\hline & Emulsion positively charged & $\begin{array}{l}\text { Enhancement of corneal } \\
\text { retention time, high levels } \\
\text { in cornea and conjunctiva }\end{array}$ & Tolerance to be evaluated & {$[66]$} \\
\hline & Microemulsions & $\begin{array}{l}\text { Improvement in dry eye } \\
\text { symptoms FDA approved }\end{array}$ & & {$[67]$} \\
\hline & $\begin{array}{l}\text { PLGA and CD } \\
\text { nanoparticles }\end{array}$ & $\begin{array}{l}\text { Enhanced retention time } \\
\text { and high cellular uptake }\end{array}$ & Tolerance to be evaluated & {$[8]$} \\
\hline & PACA nanoparticles & $\begin{array}{l}\text { Improved corneal } \\
\text { absorption }\end{array}$ & Poor tolerance & {$[68]$} \\
\hline & Chitosan nanoparticles & $\begin{array}{l}\text { Good tolerance, high } \\
\text { extraocular concentrations }\end{array}$ & Natural origin of chitosan & {$[69,70]$} \\
\hline & Liposomes & High concentrations & $\begin{array}{l}\text { Expensive and challenging } \\
\text { manufacturing }\end{array}$ & {$[66]$} \\
\hline & $\begin{array}{l}\text { Cys-PEG-SA } \\
\text { nanostructured lipid } \\
\text { carriers }\end{array}$ & High concentrations \&SR & Tolerance to be evaluated & {$[71]$} \\
\hline \multirow{4}{*}{ Topical solid forms } & Collagen shields & $\begin{array}{l}\text { Bandage effect, high levels } \\
\text { in cornea }\end{array}$ & $\begin{array}{l}\text { Patient discomfort No self } \\
\text { application }\end{array}$ & {$[72,73]$} \\
\hline & $\begin{array}{l}\text { Collagen shields }+ \\
\text { Liposomes }\end{array}$ & $\begin{array}{l}\text { Slow continuous release, } \\
\text { high tissue concentrations }\end{array}$ & $\begin{array}{l}\text { Complex manufacturing } \\
\text { methods }\end{array}$ & {$[74]$} \\
\hline & Punctal Plugs & $\begin{array}{l}\text { Double effect of both CsA } \\
\text { and the plug extended } \\
\text { release up to } 3 \text { months }\end{array}$ & Tolerance to be evaluated & {$[9]$} \\
\hline & $\begin{array}{l}\text { Silicone-hydrogel contact } \\
\text { lenses }\end{array}$ & Controlled release & $\begin{array}{l}\text { In-vivo release and toxicity } \\
\text { tests are required }\end{array}$ & {$[10]$} \\
\hline Chemically modified drugs/topical & Prodrugs & $\begin{array}{l}\text { Good tolerance, soluble in } \\
\text { water, high tear } \\
\text { concentrations }\end{array}$ & Aqueus Solubility & {$[75-77]$} \\
\hline \multirow[t]{2}{*}{ Subconjunctival liquids } & Microspheres & $\begin{array}{l}\text { High levels in cornea and } \\
\text { aqueous humor }\end{array}$ & $\begin{array}{l}\text { No benefits compared to } \\
\text { free CsA }\end{array}$ & {$[78,79]$} \\
\hline & Liposomes & $\begin{array}{l}\text { High levels at four days in } \\
\text { aqueous humor }\end{array}$ & $\begin{array}{l}\text { No benefits compared to } \\
\text { free CsA }\end{array}$ & $\begin{array}{l}{[66,79,} \\
80]\end{array}$ \\
\hline \multirow[t]{2}{*}{$\begin{array}{l}\text { Subkonjunctival/intraocular solid } \\
\text { Forms }\end{array}$} & Biodegradable implants & $\begin{array}{l}\text { Four week therapeutics } \\
\text { levels in vitreous, } \\
\text { prolongation of corneal } \\
\text { graft survival }\end{array}$ & $\begin{array}{l}\text { Implant is free in the } \\
\text { anterior chamber }\end{array}$ & {$[81]$} \\
\hline & Nonbiodegradable implants & Controlled release & $\begin{array}{l}\text { Surgical removal is } \\
\text { necessary }\end{array}$ & {$[82]$} \\
\hline
\end{tabular}

\section{(c) Colloidal Carriers}

(1) Micelles. Micelles, which are self-assembling nanosized colloidal particles with a hydrophobic core and hydrophilic shell, are successfully used as pharmaceutical carriers for water-insoluble drugs. CsA was solubilized by micelles of the nonionic surfactant, polyoxyl 40 stearate, at a concentration of $2 \% \mathrm{w} / \mathrm{v}$ [50]. After a single administration, 60 -fold higher CsA concentration was achieved in the cornea than the $0.1 \%$ w/v CsA castor oil control solution [26]. However, it was also reported that micelles are often unstable and their shelf life must be investigated [65]. 
Emulsions. Results of the early studies confirmed that emulsions could be effective topical ophthalmic drug delivery systems with a potential for sustained drug release. Particularly oil in water emulsions are useful for he delivery of lipophilic drugs. RESTASIS (CsA ophthalmic emulsion, 0.05\%) has received approval from the FDA in December 2002 as the first therapy for patients with DES [23, 93-95].

With the recent improvements in aseptic processing, and the availability of new well-tolerated emulsifiers such as polysorbate-80, emulsion technology is currently under evaluation for topical CsA delivery [67].

Liposomes. Liposomes are membrane-like vesicles consisting of one or more phospholipid bilayers alternating aqueous or lipophilic compartments, making them potential carriers for lipophilic drug like CsA. Liposomal technology has been studied for the ocular delivery of CsA by Milani et al. [66]. However, the large-scale manufacture of sterile liposomes is expensive and challenging, which make liposomes hard to apply for CsA ocular delivery. Furthermore, liposomes have short half life on the corneal surface and relatively poor stability [96].

Nanoparticles. Nanoparticles have the ability to encapsulate and protect the drug against chemical and enzymatic degradation, improve patient compliance, and increase corneal uptake. As a result of corneal uptake of the NPs, cornea acts like a reservoir and release the drug in a controlled manner. Besides, the burst release would ensure a sufficient drug level just after instillation. However, this approach still has drawbacks, such as rapid precorneal clearance [9799].

Calvo et al. [100] have prepared nanocapsules composed of an oily phase loaded with CsA (Mygliol) surrounded by a poly- $\varepsilon$-caprolactone (PCL) coat. After topical administration, these nanocapsules were taken up by corneal epithelial cells and achieved corneal levels of CsA that were five times higher than a $10 \mathrm{mg} / \mathrm{mL}$ CsA oily solution. However, the system could not provide significant CsA levels at the ocular mucosa for an extended period of time [101].

The ex vivo corneal absorption of CsA-loaded polyisobutylcyanoacrylate (PACA) nanoparticles and nanoparticles in Carbopol gel was evaluated in bovine corneas [102]. The authors found that CsA concentrations in corneas were significantly higher with nanoparticles in gel than nanoparticles alone and CsA olive oil solution. Evaluation of the in vivo tolerance and further characterization of these nanoparticles should be performed for better understanding the benefits of the system [68].

It has been investigated the potential of chitosan (CS) nanoparticles for the specific delivery of CsA to the ocular mucosa. The results showed that these systems include their ability to contact intimately with the corneal and conjunctival surfaces, thereby increasing delivery to external ocular tissues without systemic drug exposure, and to provide these target tissues with long-term drug levels. However, the natural characteristic of chitosan limits the reproducibility of the system [69].
Aksungur et al. prepared mucoadhesive Carbopol-coated nanoparticles using either PLGA or PLGA-Eudragit RL. It was reported that the PLGA: Eudragit-CsA $(75: 25)$ nanoparticles showed significantly higher degree of cellular uptake, tear film concentration (Figure 3 ) of the CsA, and $\mathrm{AUC}_{0} \rightarrow 24$ value in comparison with the other formulations [8].

The conjugate of cysteine-polyethylene glycol monostearate (Cys-PEG-SA) was synthesized and used to compose the thiolated nanostructured lipid carrier as a potential nanocarrier for the topical ocular administration of CsA. The results demonstrated that the thiolated NLC could deliver high level of CsA into intraocular tissues due to its bioadhesive property and sustained release characteristics [71].

\section{(d) Solid Dosage Forms}

Collagen Shields and Particles. Collagen-based solid systems for CsA delivery, such as shields and particles, have been developed with the purpose of enhancing the contact time of the drug with the extraocular tissue. However, such a device ported to be difficult for self-administration by patients [72].

Prodrug Approach. Another strategy to enhance the penetration of the lipophilic CsA through ocular tissues is the synthesis of a hydrophilic chemically modified molecule, which is inactive and able to transform into the active form within the tissues. It has been demonstrated that repeated local administrations of a water-soluble CsA prodrug are as efficient as systemic CsA [75].

In another study, hydroxyl group of the drug has been modified in order to improve the hydrophilicity of CsA. The results showed that the prodrug is a promising candidate in the topical treatment of dry eye disease and corneal graft rejection [76].

CsA-Loaded Punctal Plugs and Contact Lenses. A punctal plug that can also release CsA has been developed by Gupta and Chauhan [9]. Plugs, that were made of Hydroxyl ethyl methacrylate (HEMA), ethylene glycol dimethacrylate (EGDMA), and silicone, all of which are biocompatible, released CsA for about 3 months at zero-order at a rate of about $3 \mu \mathrm{g} /$ day. Pharmacokinetic models are also developed for drug delivered through Restasis and punctal plugs, and based on these models, the predictions were found to be in reasonable agreement with reported measurements in humans [9]. The punctal plug design is shown in Figure 4.

Peng and Chauhan developed a new delivery system for CsA delivery for the purpose of DES treatment using Vitamin-E-loaded silicone-hydrogel contact lenses. ACUVUE OASYS lenses were selected due to the drug release profiles and loaded with Vitamin E. The results showed that Vitamin-E-loaded lenses can provide CsA release within the therapeutic window for a period of about a month. The comparative results for the CsA release profiles of lenses that are pure or Vitamin-E-loaded are given in Figure 5. It is a promising delivery system though that in vivo release and toxicity studies are required [10]. 


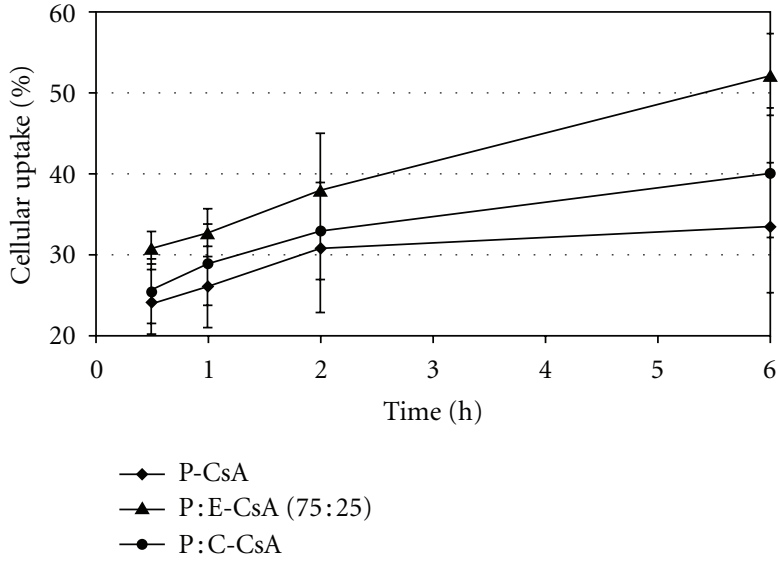

(a)

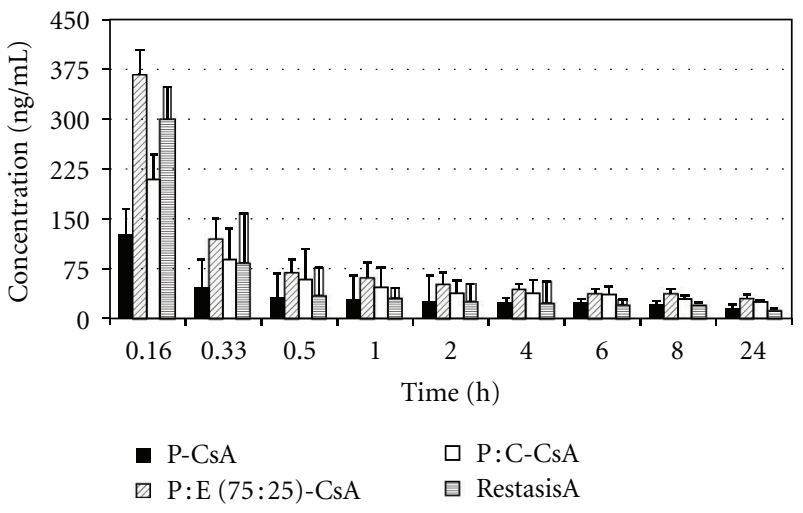

(b)

Figure 3: (a) Cellular uptake efficiency (\%) of Nile red labelled NPs, (b) CsA tear film concentration after administration of a single topical dose to rabbits $(n=6)$ [8]. (P-CsA = PLGA-CsA, P-E-CsA = PLGA : Eudragit-CsA, P-C-CsA = PLGA-Carbopol-CsA.)
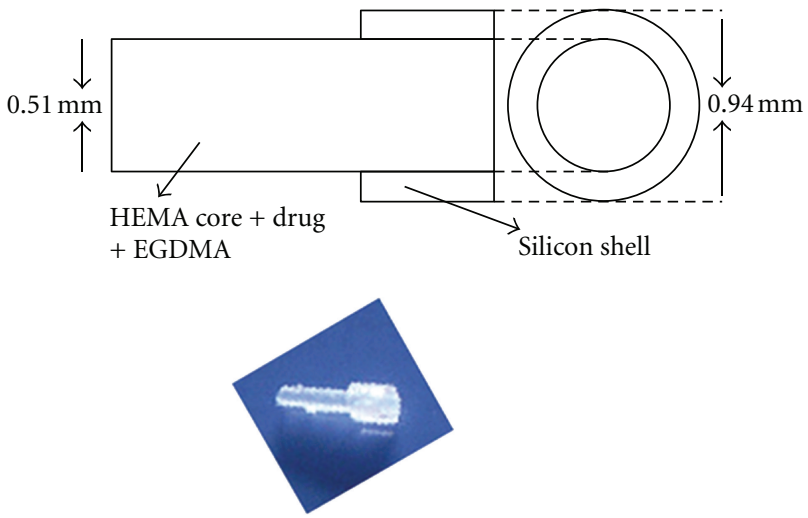

Figure 4: Schematic and image of the drug loaded punctal plug [9].

(2) Subconjunctival Administration. One of the main routes of administration for ocular therapeutics is the subconjunctival pathway. Microspheres and implants have been developed and tested after subconjunctival administration. The advantage of this approach is that it may provide high drug levels for a longer period of time in the extraocular area and its major disadvantage is its invasiveness. However, the subconjunctival route is very useful when aqueous humor is the target and solid forms allow a better controlled release.

(a) Subconjunctival Injection of Microspheres. Harper et al. prepared microspheres made of 50:50 PLGA and loaded with CsA for the purpose of maintaining high levels of CsA in the cornea and aqueous humor. Even the results of the tissue concentrations after administration were encouraging, efficacy tests were not performed [78]. Another group studied with the same type microspheres, but the formulation did not show significant differences to CsA oil solution even though the histopathology showed that the local tolerance has been improved [103]. (b) Subconjunctival Injection of Liposomes. CsA loaded liposome suspension has been prepared and injected subconjunctivally in rabbits, however, liposomes could not achieve a significant improvement comparing the tissue concentrations with free CsA. Furthermore, large-scale manufacture of sterile liposomes is expensive and technically challenging [79].

(c) Subconjunctival Injection Implants. Biodegradable PLGA copolymers of composition $85: 15$ lactide/glycolide was used to manufacture CsA-loaded implants. The advantage of this system is that it may provide therapeutic levels of CsA in about 15 days in the extraocular area, however, it requires an invasive administration [80].

\section{(3) Systemic Administration}

Intravenous Injection. CsA injection is limited due to the risk of causing anaphylactic shock and nephrotoxicity due to the solubilising agent Cremophor EL, that was used in the commercial intravenous formulation Cipol [104, 105]. Several i.v. formulations of CsA such as liposomes, microspheres, and microemulsions have been investigated to improve the therapeutic efficacy and remove the need for Cremophor EL [106]. Intravenous administration of CsA is not a common way due to the side effects mentioned above.

\section{Conclusion}

Artificial tears are the mainstay of DES therapy. Although artificial tears can improve DES symptoms of the patients and there is no evidence that they can resolve the DES dependent inflammation; thus, anti-inflammatory therapy may be indicated, including topical corticosteroids, oral tetracyclines, and CsA.

Long-term efficacy and safety of topical CsA, in the treatment of DES have been reported in literature. In contrast, 


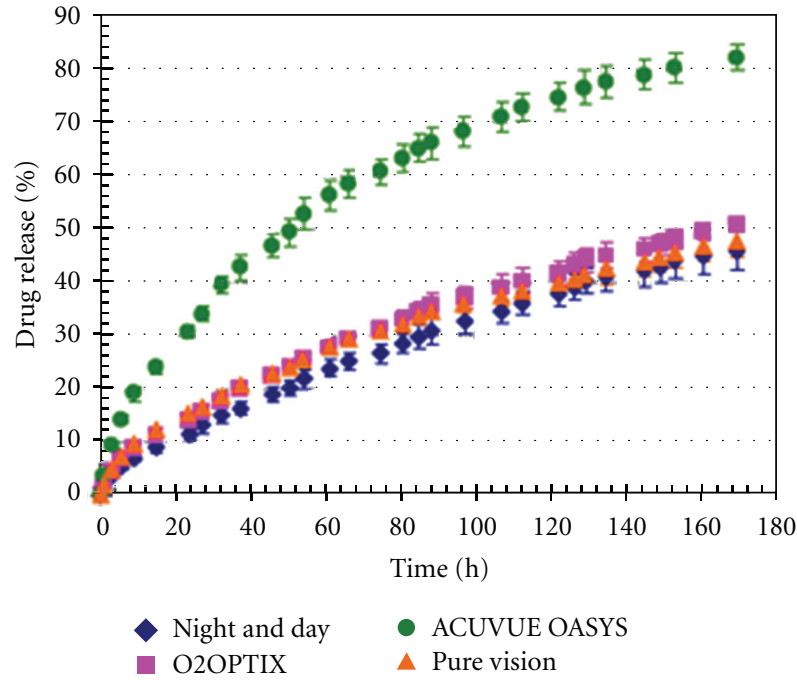

(a)

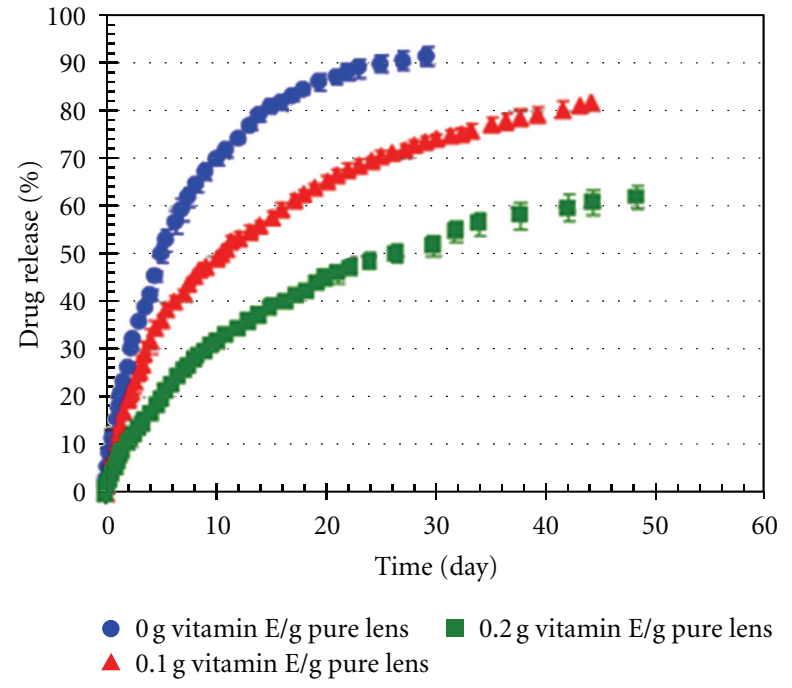

(b)

Figure 5: (a) Cumulative CsA release from silicone contact lens, (b) cumulative drug release from Vitamin E loaded ACUVUE OASYS lenses. * Data are plotted as mean $\pm \mathrm{SD}(n=3)[10]$.

even topical corticosteroids are effective, they are not recommended for long-term use because of their adverse effects. Oral tetracyclines have been used for their anti-inflammatory activity. However, this indication is off-label and is based on limited evidence. Topical NSAIDs have also been used off-label, but whether they have any role in DES has been questioned due to their side effects in some patients with compromised ocular surface.

Some of the unfavorable physicochemical properties of CsA have been improved successfully by enhancing ocular availability and improving tolerance. However, only a few formulations of CsA are commercially available and the extensive literature on the delivery of CsA reflects the great medical interest in this challenging drug. Considering topical delivery, chitosan nanoparticles, positively charged emulsions and CsA prodrugs seem to be the most promising candidates. However, none of the described topical systems has really succeeded in to extend the period of time on the corneal surface. Therefore, the administration frequency remains as a problem with these systems. CsA-loaded contact lenses may be a solution for that problem in case the further evaluations supports the in vitro results. Furthermore, sustained therapeutic levels in intraocular tissue can only be achieved by biodegradable and nonbiodegradable implants.

Different formulations may have different biological behaviours, and the choice of formulation may affect both short- and long-term clinical outcomes. There is still a lack of clinical comparisons between generic and proprietary formulations and thus, bioequivalence cannot be assumed.

\section{Acknowledgment}

The authors would like to declare that they do not have any financial relation with the commercial identities mentioned in the article.

\section{References}

[1] G. F. Schwartz, S. Kotak, J. Mardekian, and J. M. Fain, "Incidence of new coding for dry eye and ocular infection in openangle glaucoma and ocular hypertension patients treated with prostaglandin analogs: retrospective analysis of three medical/pharmacy claims databases," BMC Ophthalmology, vol. 11, no. 1, article 14, 2011.

[2] "Report of the dry eye workshop," 2007, http://www.tearfilm .org/dewsreport/.

[3] P. D. O’Brien and L. M. T. Collum, "Dry eye: diagnosis and current treatment strategies," Current Allergy and Asthma Reports, vol. 4, no. 4, pp. 314-319, 2004.

[4] S. C. Pflugfelder, "Prevalence, burden, and pharmacoeconomics of dry eye disease," American Journal of Managed Care, vol. 14, no. 3, supplement, pp. S102-S106, 2008.

[5] S. C. Pflugfelder, "Antiinflammatory therapy for dry eye," American Journal of Ophthalmology, vol. 137, no. 2, pp. 337342, 2004.

[6] M. E. Stern and S. C. Pflugfelder, "Inflammation in dry eye," Ocular Surface, vol. 2, no. 2, pp. 124-130, 2004.

[7] H. Liu, Y. Wang, and S. Li, "Advanced delivery of ciclosporin A: present state and perspective," Expert Opinion on Drug Delivery, vol. 4, no. 4, pp. 349-358, 2007.

[8] P. Aksungur, M. Demirbilek, E. B. Denkbaş, J. Vandervoort, A. Ludwig, and N. Ünlü, "Development and characterization of Cyclosporine A loaded nanoparticles for ocular drug delivery: cellular toxicity, uptake, and kinetic studies," Journal of Controlled Release, vol. 151, no. 3, pp. 286-294, 2011.

[9] C. Gupta and A. Chauhan, "Ophthalmic delivery of cyclosporine A by punctal plugs," Journal of Controlled Release, vol. 150, no. 1, pp. 70-76, 2011.

[10] C. C. Peng and A. Chauhan, "Extended cyclosporine delivery by silicone-hydrogel contact lenses," Journal of Controlled Release, vol. 154, no. 3, pp. 267-274, 2011.

[11] M. A. Lemp, "Recent developments in dry eye management," Ophthalmology, vol. 94, no. 10, pp. 1299-1304, 1987. 
[12] M. A. Lemp, "Report of the National Eye Institute/Industry workshop on Clinical Trials in Dry Eyes," The CLAO Journal, vol. 21, no. 4, pp. 221-232, 1995.

[13] P. Mertzanis, L. Abetz, K. Rajagopalan et al., "The relative burden of dry eye in patients' lives: comparisons to a U.S. normative sample," Investigative Ophthalmology \& Visual Science, vol. 46, no. 1, pp. 46-50, 2005.

[14] M. E. Stern, R. W. Beuerman, R. I. Fox, J. Gao, A. K. Mircheff, and S. C. Pflugfelder, "The pathology of dry eye: the interaction between the ocular surface and lacrimal glands," Cornea, vol. 17, no. 6, pp. 584-589, 1998.

[15] E. M. Graham, C. J. K. Ellis, M. D. Sanders, and W. I. McDonald, "Optic neuropathy in sarcoidosis," Journal of Neurology Neurosurgery and Psychiatry, vol. 49, no. 7, pp. 756-763, 1986.

[16] K. S. Kunert, A. S. Tisdale, M. E. Stern, J. A. Smith, and I. K. Gipson, "Analysis of topical cyclosporine treatment of patients with dry eye syndrome: effect on conjunctival lymphocytes," Archives of Ophthalmology, vol. 118, no. 11, pp. 1489-1496, 2000.

[17] L. G. Anderson and N. Talal, "The spectrum of benign to malignant lymphoproliferation in Sjögren's syndrome," Clinical and Experimental Immunology, vol. 10, no. 2, pp. 199-221, 1972.

[18] O. Suwan-apichon, M. Rizen, R. Rangsin et al., "Botulinum toxin B-induced mouse model of keratoconjunctivitis sicca," Investigative Ophthalmology \& Visual Science, vol. 47, no. 1, pp. 133-139, 2006.

[19] T. J. Petcher, H. P. Weber, and A. Rueegger, "Crystal and molecular structure of an iodo derivative of the cyclic undecapeptide cyclosporin A," Helvetica Chimica Acta, vol. 59, no. 5, pp. 1480-1488, 1976.

[20] N. El Tayar, A. E. Mark, P. Vallat, R. M. Brunne, B. Testa, and W. F. van Gunsteren, "Solvent-dependent conformation and hydrogen-bonding capacity of cyclosporin A: evidence from partition coefficients and molecular dynamics simulations," Journal of Medicinal Chemistry, vol. 36, no. 24, pp. 37573764, 1993.

[21] R. B. Nussenblatt, A. G. Palestine, C. C. Chan, G. Stevens Jr., S. D. Mellow, and S. B. Green, "Randomized, doublemasked study of cyclosporine compared to prednisolone in the treatment of endogenous uveitis," American Journal of Ophthalmology, vol. 112, no. 2, pp. 138-146, 1991.

[22] S. Noble and A. Markham, "Cyclosporin: a review of the pharmacokinetic properties, clinical efficacy and tolerability of a microemulsion-based formulation (Neoral)," Drugs, vol. 50, no. 5, pp. 924-941, 1995.

[23] E. Donnenfeld and S. C. Pflugfelder, "Topical ophthalmic cyclosporine: pharmacology and clinical uses," Survey of Ophthalmology, vol. 54, no. 3, pp. 321-338, 2009.

[24] K. Sall, O. D. Stevenson, T. K. Mundorf, and B. L. Reis, “Two multicenter randomized studies of the efficacy and safety of cyclosporine ophthalmic emulsion in moderate to severe dry eye disease," Ophthalmology, vol. 107, no. 4, pp. 631-639, 2000.

[25] S. E. Wilson and H. D. Perry, "Long-term resolution of chronic dry eye symptoms and signs after topical cyclosporine treatment," Ophthalmology, vol. 114, no. 1, pp. 76-79, 2007.

[26] M. Kuwano, H. Ibuki, N. Morikawa, A. Ota, and Y. Kawashima, "Cyclosporine A formulation affects its ocular distribution in rabbits," Pharmaceutical Research, vol. 19, no. 1, pp. 108-111, 2002.
[27] H. D. Perry, R. Solomon, E. D. Donnenfeld et al., "Evaluation of topical cyclosporine for the treatment of dry eye disease," Archives of Ophthalmology, vol. 126, no. 8, pp. 1046-1050, 2008.

[28] A. Behrens, J. J. Doyle, L. Stern et al., "Dysfunctional tear syndrome: a Delphi approach to treatment recommendations," Cornea, vol. 25, no. 8, pp. 900-907, 2006.

[29] M. A. Lemp, "Management of dry eye disease," American Journal of Managed Care, vol. 14, no. 3, supplement, pp. S88S110, 2008.

[30] C. A. Utine and E. K. Akpek, "What ophthalmologists should know about Sjögren's syndrome," European Ophtalmic Review, vol. 4, no. 1, pp. 77-81, 2010.

[31] A. Macri, M. Rolando, and S. Pflugfelder, "A standardized visual scale for elevation of tear fluorescein clearance," Ophthalmology, vol. 107, no. 7, pp. 1338-1343, 2000.

[32] M. Calonge, "The treatment of dry eye," Survey of Ophthalmology, vol. 45, supplement 2, pp. S227-S239, 2001.

[33] I. Toda, N. Shinozaki, and K. Tsubota, "Hydroxypropyl methylcellulose for the treatment of severe dry eye associated with Sjögren's syndrome," Cornea, vol. 15, no. 2, pp. 120-128, 1996.

[34] J. Murube, A. Murube, and C. Zhuo, "Classification of artificial tears-II: additives and commercial formulas," Advances in Experimental Medicine and Biology, vol. 438, pp. 705-715, 1998.

[35] M. Oechsner and S. Keipert, "Polyacrylic acid/polyvinylpyrrolidone bipolymeric systems-I. Rheological and mucoadhesive properties of formulations potentially useful for the treatment of dry-eye-syndrome," European Journal of Pharmaceutics and Biopharmaceutics, vol. 47, no. 2, pp. 113118, 1999.

[36] A. Ludwig, N. Unlu, and M. van Ooteghem, "Evaluation of viscous ophthalmic vehicles containing carbomer by slitlamp fluorophotometry in humans," International Journal of Pharmaceutics, vol. 61, no. 1-2, pp. 15-25, 1990.

[37] N. Unlu, A. Ludwib, M. van Ooteghem, and A. A. Hincal, "Formulation of Carbopol 940 ophthalmic vehicles, and in vitro evaluation of the influence of simulated lacrimal fluid on their physico-chemical properties," Pharmazie, vol. 46, no. 11, pp. 784-788, 1991.

[38] N. Unlu, A. Ludwig, M. van Ooteghem, and A. A. Hincal, "A comparative rheological study on carbopol viscous solutions and, the evaluation of their suitability as the ophthalmic vehicles and artificial tears," Pharmaceutica Acta Helvetiae, vol. 67, no. 1, pp. 5-10, 1992.

[39] J. L. Ubels, M. D. McCartney, W. K. Lantz, J. Beaird, A. Dayalan, and H. F. Edelhauser, "Effects of preservative-free artificial tear solutions on corneal epithelial structure and function," Archives of Ophthalmology, vol. 113, no. 3, pp. 371378, 1995.

[40] G. Geerling, S. MacLennan, and D. Hartwig, "Autologous serum eye drops for ocular surface disorders," British Journal of Ophthalmology, vol. 88, no. 11, pp. 1467-1474, 2004.

[41] S. Schrader, T. Wedel, R. Moll, and G. Geerling, "Combination of serum eye drops with hydrogel bandage contact lenses in the treatment of persistent epithelial defects," Graefe's Archive for Clinical and Experimental Ophthalmology, vol. 244, no. 10, pp. 1345-1349, 2006.

[42] P. I. Burgess, P. Koay, and P. Clark, "SmartPlug versus silicone punctal plug therapy for dry eye: a prospective randomized trial," Cornea, vol. 27, no. 4, pp. 391-394, 2008. 
[43] M. T. Yen, S. C. Pflugfelder, and W. J. Feuer, "The effect of punctal occlusion on tear production, tear clearance, and ocular surface sensation in normal subjects," American Journal of Ophthalmology, vol. 131, no. 3, pp. 314-323, 2001.

[44] S. C. Pflugfelder, D. Jones, Z. Ji, A. Afonso, and D. Monroy, "Altered cytokine balance in the tear fluid and conjunctiva of patients with Sjogren's syndrome keratoconjunctivitis sicca," Current Eye Research, vol. 19, no. 3, pp. 201-211, 1999.

[45] G. N. Foulks, "The evolving treatment of dry eye," Ophthalmology Clinics of North America, vol. 16, no. 1, pp. 29-35, 2003.

[46] M. J. Quarterman, D. W. Johnson, D. C. Abele, J. L. Lesher Jr., D. S. Hull, and L. S. Davis, "Ocular rosacea: signs, symptoms, and tear studies before and after treatment with doxycycline," Archives of Dermatology, vol. 133, no. 1, pp. 49-54, 1997.

[47] W. D. Mathers, D. Stovall, J. A. Lane, M. B. Zimmerman, and S. Johnson, "Menopause and tear function: the influence of prolactin and sex hormones on human tear production," Cornea, vol. 17, no. 4, pp. 353-358, 1998.

[48] S. Sahlin, E. Chen, T. Kaugesaar, H. Almqvist, K. Kjellberg, and G. Lennerstrand, "Effect of eyelid botulinum toxin injection on lacrimal drainage," American Journal of Ophthalmology, vol. 129, no. 4, pp. 481-486, 2000.

[49] R. Avisar, A. Robinson, I. Appel, Y. Yassur, and D. Weinberger, "Diclofenac sodium, $0.1 \%$ (Voltaren Ophtha), versus sodium chloride, $5 \%$, in the treatment of filamentary keratitis," Cornea, vol. 19, no. 2, pp. 145-147, 2000.

[50] B. A. Schechter, "Ketorolac during the induction phase of cyclosporin-A therapy," Journal of Ocular Pharmacology and Therapeutics, vol. 22, no. 2, pp. 150-154, 2006.

[51] W. D. Mathers and A. M. Dolney, "Objective demonstration of tear stimulation with oral pilocarpine in dry eye patients," Investigative Ophthalmology \& Visual Science, vol. 41, no. 4, article S60, 2000.

[52] E. C. Kim, J. S. Choi, and C. K. Joo, "A comparison of vitamin A and cyclosporine A $0.05 \%$ eye drops for treatment of dry eye syndrome," American Journal of Ophthalmology, vol. 147, no. 2, pp. 206-213, 2009.

[53] H. Selek, N. Ünlü, and A. A. Hincal, "An ophthalmic emulsion of retinoic acid," S.T.P. Pharma Sciences, vol. 8, no. 5, pp. 323-326, 1998.

[54] H. Selek, N. Ünlü, M. Orhan, and M. Irkeç, "Evaluation of retinoic acid ophthalmic emulsion in dry eye," European Journal of Ophthalmology, vol. 10, no. 2, pp. 121-127, 2000.

[55] Y. Çirpanli, N. Ünlü, S. Çaliş, and A. A. Hincal, "Formulation and in-vitro characterization of retinoic acid loaded poly (lactic-co-glycolic acid) microspheres," Journal of Microencapsulation, vol. 22, no. 8, pp. 877-889, 2005.

[56] H. F. Stähelin, "The history of cyclosporin a (Sandimmune) revisited: another point of view," Experientia, vol. 52, no. 1, pp. 5-13, 1996.

[57] R. M. Wenger, "Synthesis of cyclosporine. Total syntheses of "cyclosporin A" and "cyclosporin H", two fungal metabolites isolated from the species Tolypocladium inflatum GAMS," Helvetica Chimica Acta, vol. 67, no. 2, pp. 502-525, 1984.

[58] D. L. Williams, "A comparative approach to topical cyclosporine therapy," Eye, vol. 11, no. 4, pp. 453-464, 1997.

[59] D. BenEzra, G. Maftzir, C. de Courten, and P. Timonen, "Ocular penetration of cyclosporin A-III: the human eye," British Journal of Ophthalmology, vol. 74, no. 6, pp. 350-352, 1990.

[60] D. K. Olivero, M. G. Davidson, R. V. English, M. P. Nasisse, V. E. Jamieson, and T. M. Gerig, "Clinical evaluation of $1 \%$ cyclosporine for topical treatment of keratoconjunctivitis sicca in dogs," Journal of the American Veterinary Medical Association, vol. 199, no. 8, pp. 1039-1042, 1991.

[61] C. Newton, B. M. Gebhardt, and H. E. Kaufman, "Topically applied cyclosporine in azone prolongs corneal allograft survival," Investigative Ophthalmology \& Visual Science, vol. 29, no. 2, pp. 208-215, 1988.

[62] L. Cheeks, R. L. Kaswan, and K. Green, "Influence of vehicle and anterior chamber protein concentration on cyclosporine penetration through the isolated rabbit cornea," Current Eye Research, vol. 11, no. 7, pp. 641-649, 1992.

[63] P. Furrer, J. M. Mayer, B. Plazonnet, and R. Gurny, "Ocular tolerance of preservatives on the murine cornea," European Journal of Pharmaceutics and Biopharmaceutics, vol. 47, no. 2, pp. 105-112, 1999.

[64] D. D. S. Tang-Liu, J. B. Richman, R. J. Weinkam, and H. Takruri, "Effects of four penetration enhancers on corneal permeability of drugs in vitro," Journal of Pharmaceutical Sciences, vol. 83, no. 1, pp. 85-90, 1994.

[65] S. Hickok, "Polyoxyethylene stearate," in Handbook of Pharmaceutical Excipients, A. Wade and W. Paul, Eds., pp. 379384, The Pharmaceutical Press, London, UK, 1994.

[66] J. K. Milani, U. Pleyer, A. Dukes et al., "Prolongation of corneal allograft survival with liposome-encapsulated cyclosporine in the rat eye," Ophthalmology, vol. 100, no. 6, pp. 890-896, 1993.

[67] S. Ding and C. A. Irvine, "Nonirritating emulsions for sensitive tissue," U.S. Patent 5,474,979, 1995.

[68] A. Zimmer, J. Kreuter, and J. R. Robinson, "Studies on the transport pathway of PBCA nanoparticles in ocular tissues," Journal of Microencapsulation, vol. 8, no. 4, pp. 497-504, 1991.

[69] A. M. De Campos, A. Sánchez, and M. J. Alonso, "Chitosan nanoparticles: a new vehicle for the improvement of the delivery of drugs to the ocular surface. Application to cyclosporin A," International Journal of Pharmaceutics, vol. 224, no. 1-2, pp. 159-168, 2001.

[70] O. Felt, P. Furrer, J. M. Mayer, B. Plazonnet, P. Buri, and R. Gurny, "Topical use of chitosan in ophthalmology: tolerance assessment and evaluation of precorneal retention," International Journal of Pharmaceutics, vol. 180, no. 2, pp. 185-193, 1999.

[71] J. Shen, Y. Deng, X. Jin, Q. Ping, Z. Su, and L. Li, “Thiolated nanostructured lipid carriers as a potential ocular drug delivery system for cyclosporine A: improving in vivo ocular distribution," International Journal of Pharmaceutics, vol. 402, no. 1-2, pp. 248-253, 2010.

[72] J. J. Reidy, B. M. Gebhardt, and H. E. Kaufman, "The collagen shield: a new vehicle for delivery of cyclosporin A to the eye," Cornea, vol. 9, no. 3, pp. 196-199, 1990.

[73] U. Pleyer, B. Elkins, D. Ruckert et al., "Ocular absorption of cyclosporine A from liposomes incorporated into collagen shields," Current Eye Research, vol. 13, no. 3, pp. 177-181, 1994.

[74] B. M. Gebhardt and H. E. Kaufman, "Collagen as a delivery system for hydrophobic drugs: studies with cyclosporine," Journal of Ocular Pharmacology and Therapeutics, vol. 11, no. 3, pp. 319-327, 1995.

[75] J. L. Bourges, F. Lallemand, E. Agla et al., "Evaluation of a topical cyclosporine A prodrug on corneal graft rejection in rats," Molecular Vision, vol. 12, pp. 1461-1466, 2006.

[76] F. Lallemand, P. Furrer, O. Felt-Baeyens et al., "A novel watersoluble cyclosporine A prodrug: ocular tolerance and in vivo kinetics," International Journal of Pharmaceutics, vol. 295, no. 1-2, pp. 7-14, 2005. 
[77] D. Meadows, "Nonaqueous fluorinated drug delivery vehicle suspensions," Patent US, 1992.

[78] C. A. Harper III, B. Khoobehi, G. A. Peyman, B. M. Gebhardt, and W. A. Dunlap, "Bioavailability of microsphereentrapped cyclosporine $\mathrm{A}$ in the cornea and aqueous of rabbits," International Ophthalmology, vol. 17, no. 6, pp. 337340, 1993.

[79] A. A. Alghadyan, G. A. Peyman, B. Khoobehi, S. Milner, and K. R. Liu, "Liposome-bound cyclosporine: aqueous and vitreous level after subconjunctival injection," International Ophthalmology, vol. 12, no. 2, pp. 101-104, 1988.

[80] A. Apel, C. Oh, R. Chiu, B. Saville, Y. L. Cheng, and D. Rootman, "A subconjunctival degradable implant for cyclosporine delivery in corneal transplant therapy," Current Eye Research, vol. 14, no. 8, pp. 659-667, 1995.

[81] J. Grisolano Jr. and G. A. Peyman, "Retinal toxicity study of intravitreal cyclosporin," Ophthalmic Surgery, vol. 17, no. 3, pp. 155-156, 1986.

[82] G. J. Jaffe, C. S. Yang, X. C. Wang, S. W. Cousins, R. P. Gallemore, and P. Ashton, "Intravitreal sustained-release cyclosporine in the treatment of experimental uveitis," Ophthalmology, vol. 105, no. 1, pp. 46-56, 1998.

[83] J. D. Nelson, H. Helms, R. Fiscella, Y. Southwell, and J. D. Hirsch, "A new look at dry eye disease and its treatment," Advances in Therapy, vol. 17, no. 2, pp. 84-93, 2000.

[84] M. M. Brown, G. C. Brown, H. C. Brown, J. Peet, and Z. Roth, "Value-based medicine, comparative effectiveness, and cost-effectiveness analysis of topical cyclosporine for the treatment of dry eye syndrome," Archives of Ophthalmology, vol. 127, no. 2, pp. 146-152, 2009.

[85] E. Adriaens, K. Dierckens, T. G. M. Bauters et al., "The mucosal toxicity of different benzalkonium chloride analogues evaluated with an alternative test using slugs," Pharmaceutical Research, vol. 18, no. 7, pp. 937-942, 2001.

[86] D. Monti, P. Chetoni, S. Burgalassi, M. Najarro, and M. F. Saettone, "Increased corneal hydration induced by potential ocular penetration enhancers: assessment by differential scanning calorimetry (DSC) and by desiccation," International Journal of Pharmaceutics, vol. 232, no. 1-2, pp. 139147, 2002.

[87] B. Yavuz, E. Bilensoy, I. Vural, and M. Şumnu, “Alternative oral exemestane formulation: improved dissolution and permeation," International Journal of Pharmaceutics, vol. 398, no. 1-2, pp. 137-145, 2010.

[88] A. Kanai, R. M. Alba, T. Takano et al., "The effect on the cornea of alpha cyclodextrin vehicle for cyclosporin eye drops," Transplantation Proceedings, vol. 21, no. 1, part 3, pp. 31503152, 1989.

[89] D. W. Mueller, "Improved extemporaneous formulation of cyclosporine ophthalmic drops," American Journal of Hospital Pharmacy, vol. 51, no. 24, pp. 3080-3081, 1994.

[90] S. N. Rao, "Topical cyclosporine $0.05 \%$ for the prevention of dry eye disease progression," Journal of Ocular Pharmacology and Therapeutics, vol. 26, no. 2, pp. 157-164, 2010.

[91] S. Solch, P. I. Nadler, and M. H. Silverman, "Safety and tolerability of two percent cyclosporine (Sandimmune) ophthalmic ointment in normal volunteers," Journal of Ocular Pharmacology, vol. 7, no. 4, pp. 301-312, 1991.

[92] J. Sansom, K. C. Barnett, W. Neumann et al., "Treatment of keratoconjunctivitis sicca in dogs with cyclosporine ophthalmic ointment: a European clinical field trial," Veterinary Record, vol. 137, no. 20, pp. 504-507, 1995.
[93] S. Muchtar, S. Almog, M. T. Torracca, M. F. Saettone, and S. Benita, "A submicron emulsion as ocular vehicle for delta-8tetrahydrocannabinol: effect on intraocular pressure in rabbits," Ophthalmic Research, vol. 24, no. 3, pp. 142-149, 1992.

[94] N. Naveh, S. Muchtar, and S. Benita, "Pilocarpine incorporated into a submicron emulsion vehicle causes an unexpectedly prolonged ocular hypotensive effect in rabbits," Journal of Ocular Pharmacology, vol. 10, no. 3, pp. 509-520, 1994.

[95] F. Lallemand, O. Felt-Baeyens, K. Besseghir, F. Behar-Cohen, and R. Gurny, "Cyclosporine A delivery to the eye: a pharmaceutical challenge," European Journal of Pharmaceutics and Biopharmaceutics, vol. 56, no. 3, pp. 307-318, 2003.

[96] S. L. Law, K. J. Huang, and C. H. Chiang, "Acyclovircontaining liposomes for potential ocular delivery: corneal penetration and absorption," Journal of Controlled Release, vol. 63, no. 1-2, pp. 135-140, 2000.

[97] S. S. Lee, H. Kim, N. S. Wang et al., "A pharmacokinetic and safety evaluation of an episcleral cyclosporine implant for potential use in high-risk keratoplasty rejection," Investigative Ophthalmology \& Visual Science, vol. 48, no. 5, pp. 20232029, 2007.

[98] S. Bozdag, K. Dillen, J. Vandervoort, and A. Ludwig, "The effect of freeze-drying with different cryoprotectants and gamma-irradiation sterilization on the characteristics of ciprofloxacin HCl-loaded poly(D,L-lactide-glycolide) nanoparticles," Journal of Pharmacy and Pharmacology, vol. 57, no. 6, pp. 699-707, 2005.

[99] K. Dillen, S. Bozdag, J. Vandervoort, and A. Ludwig, "Evaluation of the physicochemical characteristics and activity of various kinds of ciprofloxacin HCl-loaded cationic nanoparticles," Journal of Drug Delivery Science and Technology, vol. 17, no. 1, pp. 49-56, 2007.

[100] B. Calvo, A. Sanchez, J. Martinez et al., "Polyester nanocapsules as new topical ocular delivery systems for cyclosporin A," Pharmaceutical Research, vol. 13, no. 2, pp. 311-315, 1996.

[101] P. Calvo, C. Thomas, M. J. Alonso, J. L. Vila-Jato, and J. R. Robinson, "Study of the mechanism of interaction of poly $(\varepsilon$ caprolactone) nanocapsules with the cornea by confocal laser scanning microscopy," International Journal of Pharmaceutics, vol. 103, no. 3, pp. 283-291, 1994.

[102] C. A. Le Bourlais, F. Chevanne, B. Turlin et al., "Effect of cyclosporine A formulations on bovine corneal absorption: ex-vivo study," Journal of Microencapsulation, vol. 14, no. 4, pp. 457-467, 1997.

[103] M. V. de Rojas Silva, M. T. Rodríguez-Ares, M. SánchezSalorio et al., "Efficacy of subconjunctival cyclosporincontaining microspheres on keratoplasty rejection in the rabbit," Graefe's Archive for Clinical and Experimental Ophthalmology, vol. 237, no. 10, pp. 840-847, 1999.

[104] T. Cavanak and H. Sucker, "Cyclosporin. Formulation of dosage forms," Progress in Allergy, vol. 38, pp. 65-72, 1986.

[105] A. Besarab, B. E. Jarrell, and S. Hirsch, "Use of the isolated perfused kidney model to assess the acute pharmacologic effects of cyclosporine and its vehicle, cremophor EL," Transplantation, vol. 44, no. 2, pp. 195-201, 1987.

[106] C. E. Freise, T. Liu, K. Hong et al., "The increased efficacy and decreased nephrotoxicity of a cyclosporine liposome," Transplantation, vol. 57, no. 6, pp. 928-932, 1994. 


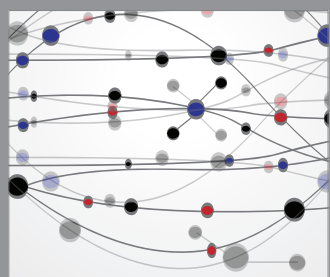

The Scientific World Journal
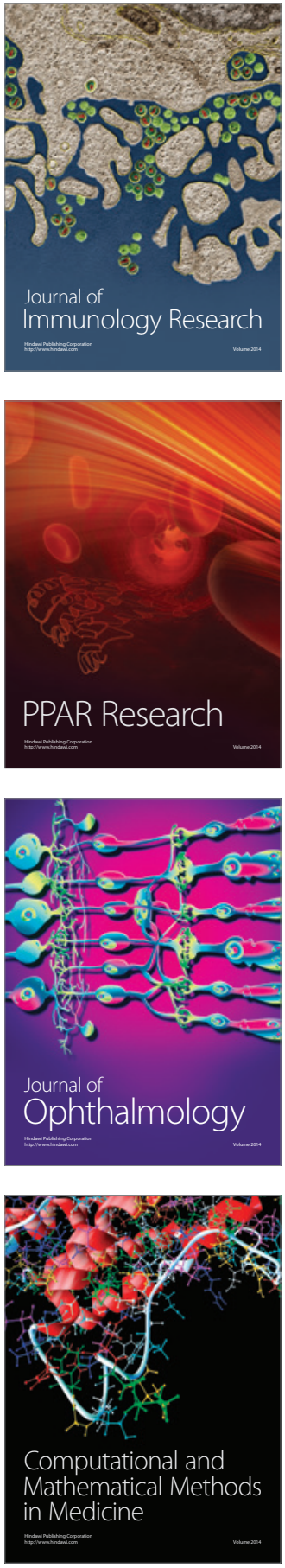

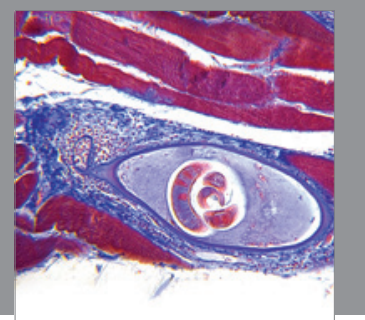

Gastroenterology

Research and Practice
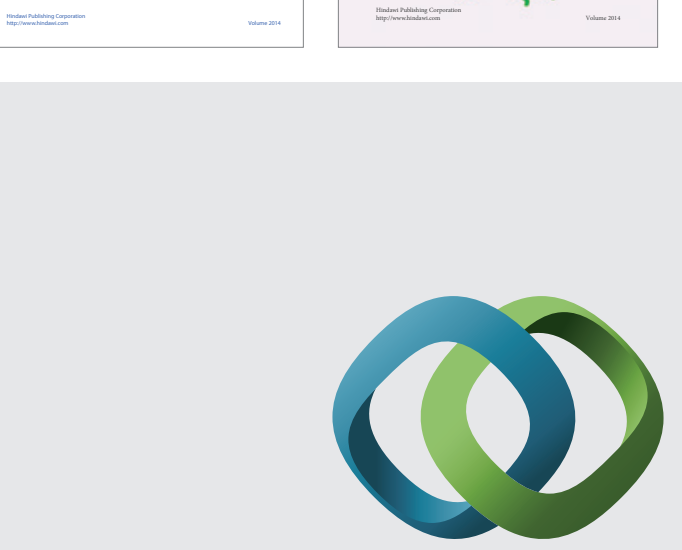

\section{Hindawi}

Submit your manuscripts at

http://www.hindawi.com
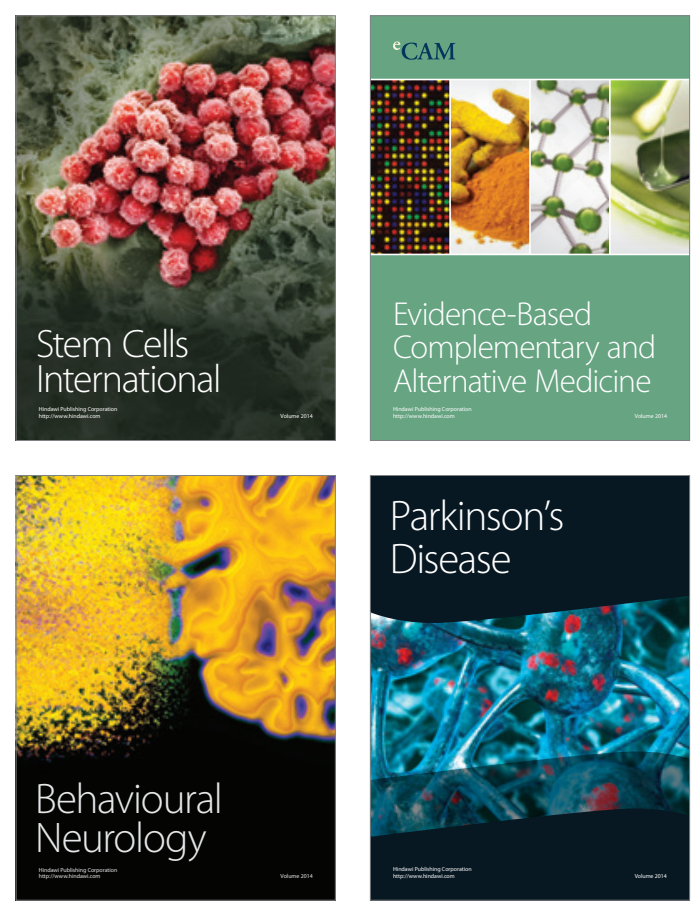

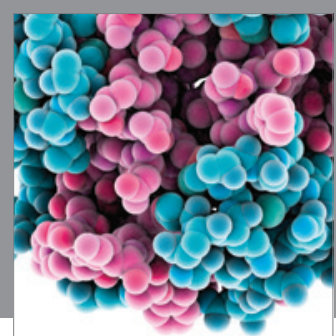

Journal of
Diabetes Research

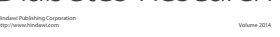

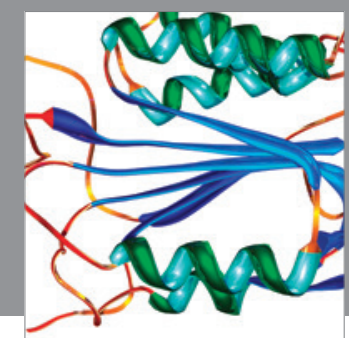

Disease Markers
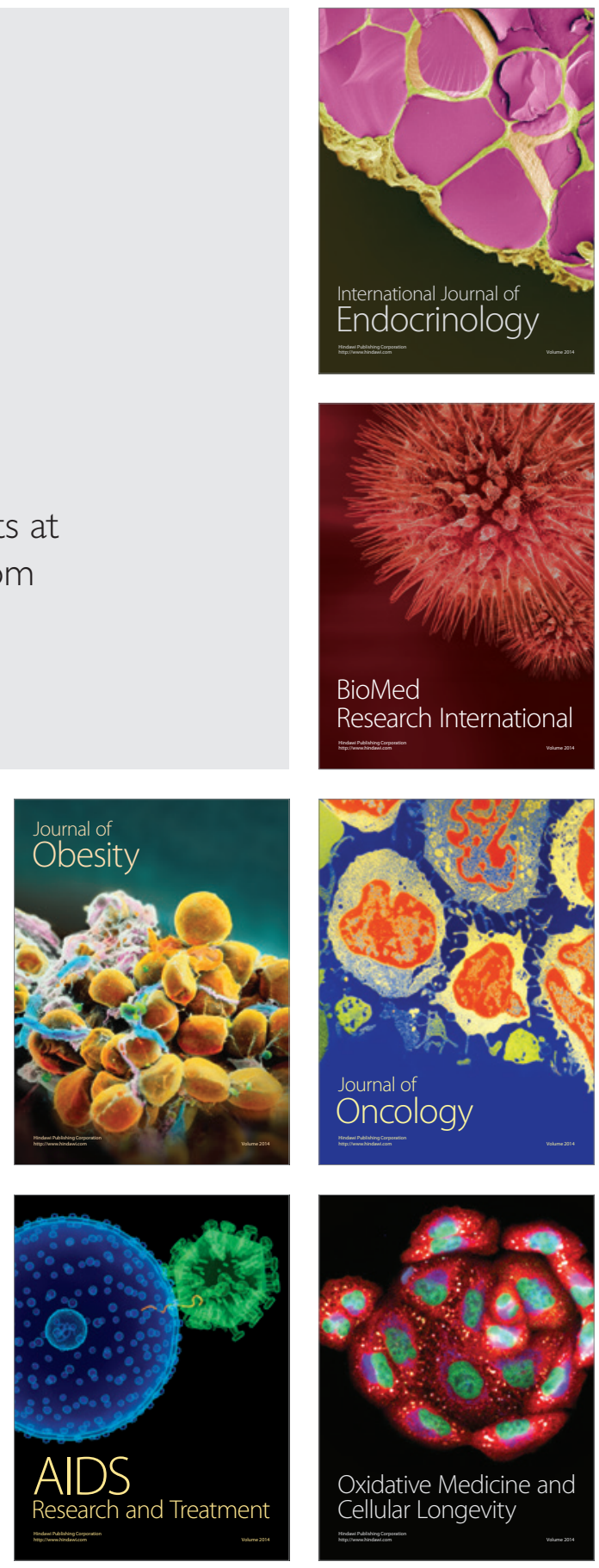